\title{
Spontaneous idiopathic omental haemorrhage: a rare cause of right iliac fossa pain
}

Nima Ahmadi ${ }^{1,2^{*}}$, Jonathan S. Y. Hong ${ }^{1,2}$ and William S. Mackie ${ }^{1}$

\begin{abstract}
Background: Isolated omental haemorrhage is a rare entity of which only case reports exist. This is usually in the setting of trauma, neoplasms or anticoagulation.

Case presentation: We report a case of spontaneous idiopathic omental haemorrhage with no evidence of trauma, neoplasm or presence of anticoagulation. This was identified on the imaging studies performed for the purpose of diagnosis of the cause of the patient's right iliac fossa pain. The patient required urgent laparotomy and omentectomy to achieve haemostasis.

Discussion: Spontaneous omental haemorrhage is a rare entity that is usually preceeded by trauma or occurs in the context of adhesions, neoplasms or anticoagulation. If there are delays in diagnosis, it could lead to significant morbidity for the patient. Therefore, it requires prompt recognition and definitive management.

Conclusion: Spontaneous omental haemorrhage is a rare entity characterised only in case reports. It is usually a secondary event and requires prompt management.
\end{abstract}

Keywords: Omental haemorrhage, Haemoperitoneum

\section{Background}

Omental haemorrhage leading to significant haemoperitoneum is a rare entity. Within the literature, the only publications of spontaneous omental bleeding are case reports [1-4]. The secondary causes include trauma, neoplasms [5], varices [6, 7], adhesions [8, 9], torsion [10], arterial aneurysm [11, 12], vasculitis [13] and omental pregnancies [14-16].

Idiopathic omental haemorrhage typically presents with severe sudden onset pain and occasional nausea, vomiting or diarrhoea [1-3]. This can mimic other more common causes of abdominal pain. The management involves initial resuscitation, correction of coagulopathy, if present, followed by imaging if the haemodynamics of the patient allow.

Imaging may include focused assessment with sonography, which has been used to detect acute intraperitoneal

\footnotetext{
* Correspondence: nimaahmadi100@gmail.com

'Department of Surgery, Orange Health Service, Orange, NSW, Australia

${ }^{2}$ Surgical Outcome Research Centre (SOuRCe), Royal Prince Alfred Hospital, Missenden Rd, Camperdown, 2050 Sydney, NSW, Australia
}

haemorrhage [17]. Contrast computed tomography is useful to localise the site of bleeding and exclude more common pathology $[2,3,17]$. Formal arterial angiography may permit ultra-selective embolisation, but its use is limited by availability of this modality [3]. However, within the literature, the majority of reported cases have proceeded to laparotomy and partial omentectomy.

Below, we report a case of spontaneous idiopathic omental rupture leading to haemoperitoneum needing operative management.

\section{Case presentation}

A 53-year-old gentleman presented to our emergency department with a 4-h history of right iliac fossa and right periumbilical pain. There was no history of trauma. The onset of pain was sudden, and it was intermittent in nature and worse on movement. He denied nausea or other gastrointestinal symptoms.

The patient had background of atrial fibrillation (AF) but was not anticoagulated. There was no history of abdominal surgery. 
On presentation, his heart rate was $100 \mathrm{bpm}$ and he was in $\mathrm{AF}$, with a blood pressure of $142 / 90 \mathrm{mmHg}$. He had focal peritonism in the right lumbar region and right hypochondrium.

Initial blood tests showed his haemoglobin to be $143 \mathrm{~g} / \mathrm{L}$, white cell count of $9.6 \times 10^{9} / \mathrm{L}$, platelet count of $270 \times 10^{9} / \mathrm{L}$.

A CT abdomen demonstrated free high attenuation fluid around the liver and the right paracolic gutter. An area of high attenuation was noted at the right lateral anterior abdominal wall with contrast extravasation on both arterial and porto-venous phases suspicious for an omental haemorrhage and haematoma (see Fig. 1).

At laparotomy, there was $2 \mathrm{~L}$ of free blood. There were no adhesions or varices. A large haematoma was noted within the right upper quadrant omentum, but there was no active bleeding. Within this segment of omentum, an abnormal area was identified as a possible point of bleeding. This was resected.

The patient was discharged after 4 days.

The histopathological demonstrated ruptured mediumsized vessels at the site of macroscopic abnormality, there was no vasculitis or malignancy (Fig. 2). The remainder of the specimen was histopathologically normal.

\section{Conclusion}

Isolated, primary omental haemorrhage is a rare entity that is characterised only in case reports. Secondary causes include trauma, neoplasm, adhesion or anticoagulation.

Patients typically present with severe sudden onset pain and occasional nausea, vomiting or diarrhoea [1-3]. Management involves resuscitation, correction of coagulopathy, followed by imaging, if the patient is stable.

Imaging may include focused assessment with sonography, which has been used to detect acute intraperitoneal haemorrhage [17]. Contrast computed tomography is useful to localise the site of bleeding and exclude more common pathology [2, 3, 17]. Formal arterial angiography may permit ultra-selective embolisation, but its use is limited by availability of this modality [3].

The majority of reported cases proceed to laparotomy and partial omentectomy. There is one case report of a laparoscopic approach to management [18]; however, similar to our case, the surgeons had difficulty identifying the bleeding point and had to increase their incision to perform an extracorporeal evaluation of the omentum and perform a partial omentectomy. Similarly, in our case, there was no active bleeding identified at the time of the operation and our approach with a laparotomy
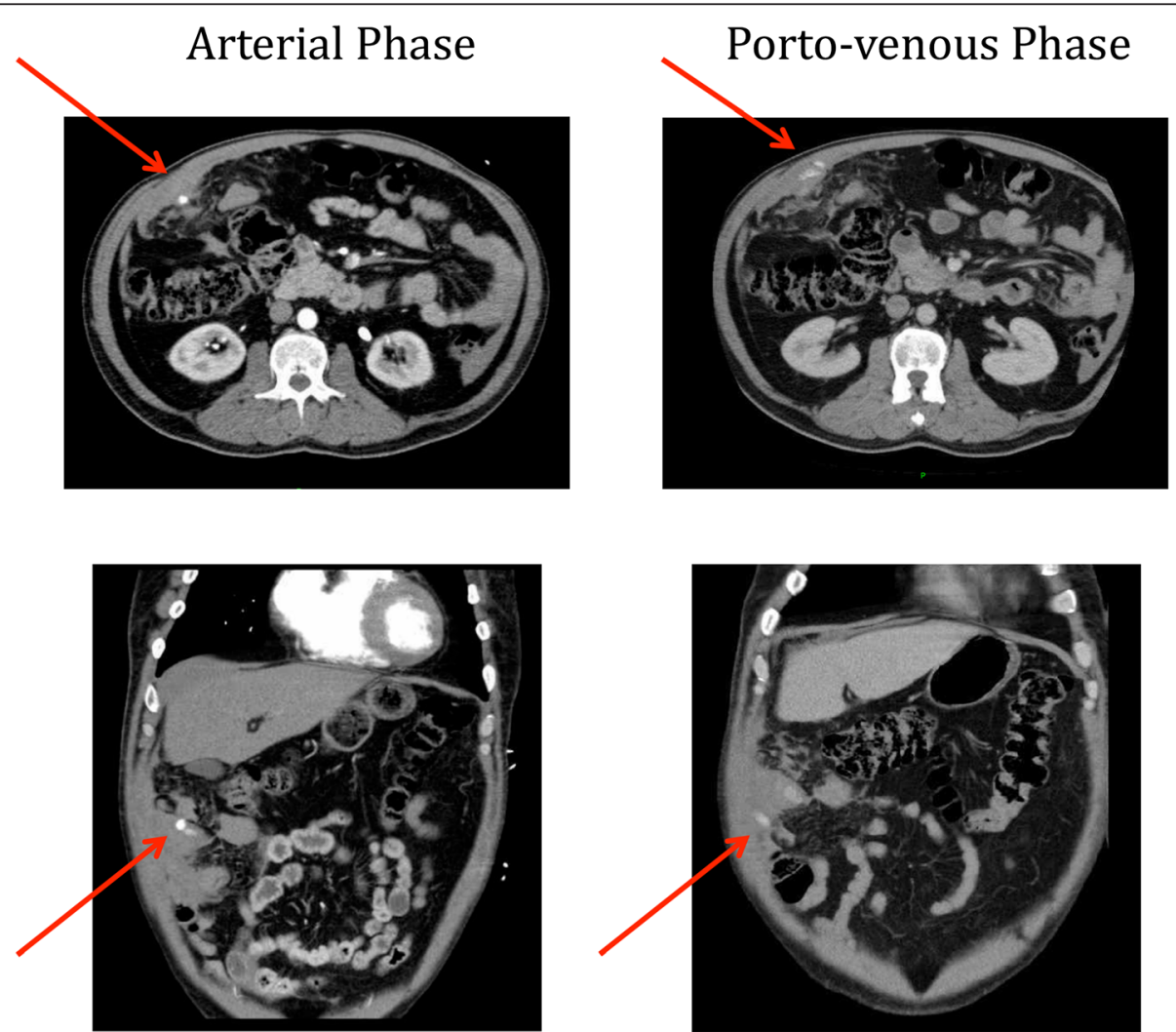

Fig. $1 \mathrm{CT}$ abdomen/pelvis with IV contrast with arterial and porto-venous phases demonstrating blush (arrows) and free high attenuation fluid in the peritoneum 


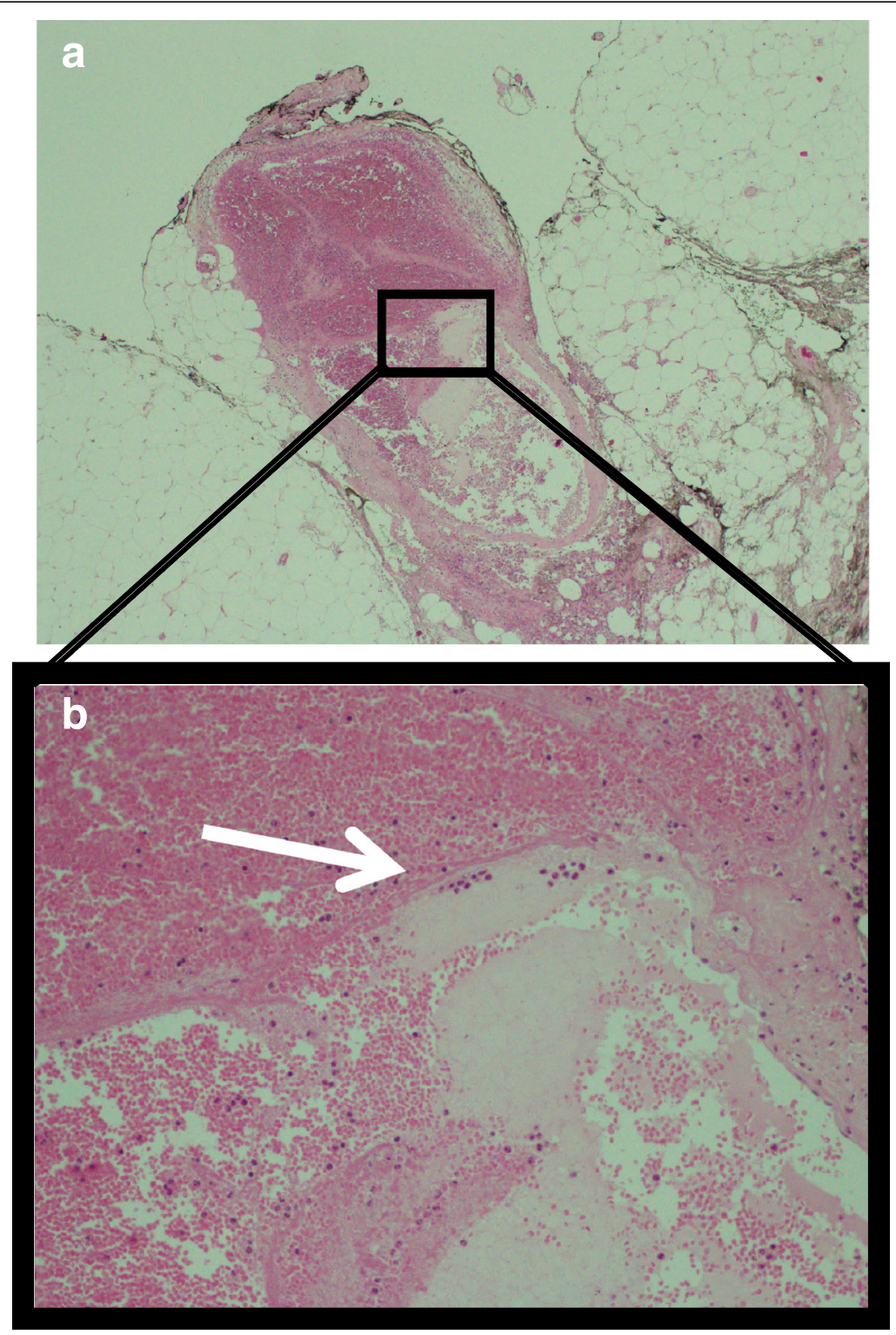

Fig. 2 Histological slide with H\&E staining (a). The magnified image (b) demonstrating a ruptured vessel (arrow) with extraluminal blood within the omentum. There was no evidence of neoplastic or vasculitic change

and partial omentectomy permitted histopathological assessment of the affected omentum to exclude other causes of omental bleeding.

Given that spontaneous omental haemorrhage is such a rare entity, a stepwise approach should be taken for patients presenting with abdominal pain and it is wise to remember that common things occur commonly. However, one should always have an index of suspicion for identifying unexpected pathology as such in this case.

\section{Consent}

Written informed consent was obtained from the patient for publication of this case report and any accompanying images. A copy of the written consent is available for review by the Editor-in-Chief of this journal.

\section{Abbreviations}

AF: atrial fibrillation; CT: computed tomography.

\section{Competing interests}

The authors declare that they have no competing interests.

\section{Authors' contributions}

NA performed literature review and drafted the manuscript. JH edited and critically revised the manuscript. WM critically revised the manuscript and has given final approval of publication. All authors read and approved the final manuscript. 
Received: 29 December 2015 Accepted: 7 April 2016

Published online: 14 April 2016

\section{References}

1. Eberts EM. Case of spontaneous haemorrhage from the great omentum. Can Med Assoc J. 1920;10(5):461-3.

2. Bhandari RS, Sapkota R, Mishra P, Singh KP. Spontaneous omental hematoma. J Inst Med. 2009;31(1):20-2.

3. Matsumoto T, Yamagami T, Morishita H, lida S, Tazoe J, Asai S, Masui K, Ikeda J, Nagata A, Sato O, Nishimura T. Transcatheter arterial embolization for spontaneous rupture of the omental artery. Cardiovasc Intervent Radiol. 2011;34:S142-5.

4. Cheng VE, Oppermen A, Natarajan D, Haikerwal D, Pereira J. Spontaneous omental bleeding in the setting of dual anti-platelet therapy with ticagrelor. Heart Lung Circ. 2014;23:e115-7.

5. Rye BAO, Christiansen E, Larsen LG. Acute bleeding from leiomyoblastoma of the greater omentum - a case report. Tumori. 1989;75:296-8.

6. Finley DS, Lugo B, Ridgway J, Teng W, Imagawa DK. Fatal variceal rupture after sildenafil use: report of a case. Curr Surg. 2005;62(1):55-6.

7. Ragupathi K, Bloom A, Pai N. Hemoperitoneum from ruptured omental varices. J Clin Gastroenterol. 1985;7:537-8.

8. Ohno T, Ogata K, Aiba S, Fukuchi M, Osawa H, Mogi A, Motegi M, Nagashima K, Ishizaki M, Mochiki E, Kuwano H. Idiopathic omental bleeding: report of a case. Surg Today. 2005;35:493-5.

9. Henry D, Satgunam S. Idiopathic omental bleeding. J Surg Case Rep. 2012;9:2.

10. Nihei Z, Kojima K, Uehara K, Sawai S, Kakihana M, Hirayama R, Mishima Y. Omental bleeding with spontaneously derotated torsion: a case report. Jpn J Surg. 1991;21(6):700-2.

11. Bettini N, Goueffic Y, Marret O, Heymann MF, Costargent A, Patra P, Chaillou $P$. Hemoperitoneum due to rupture of an omental arterial aneurysm. J Chi (Paris). 2007;144(6):544-5

12. Park DJ, Oh KH, Kim SJ, Joo KW, Han JS, Kim S, Lee JS, Ahn C. True aneurysm rupture of omental artery leading to hemoperitoneum and shock in a CAPD patient. Nephrol Dial Transplant. 2005;20:2292.

13. Kroot EJ, Mak CL, Boelhouwer RU, Middelkoop MP, Dees A. Involvement of the omentum in Wegener's granulomatosis. Ann Rheum Dis. 2003;62:1238-9.

14. Onan MA, Turp AB, Saltk A, Akyurek N, Taskiran C, Himmetoglu O. Primary omental pregnancy: case report. Hum Reprod. 2005;20(3):807-9.

15. Oznur K, Ozer I, Semra O. Primary omental pregnancy on the gastrocolic ligament. South Med J. 2007;100(4):403-4.

16. Tanaka Y, Yokoyama M, Onoyama Y, Nozaki M, Nakano H. Abdominal bleeding from omental trophoblastic implants after laparoscopic salpingostomy. J Gyn Surg. 2002;18(4):167-70.

17. Mortele KJ, Cantisani V, Brown DL, Ros PR. Spontaneous intraperitoneal hemorrhage: imaging features. Radiol Clin N Am. 2003;41:1183-201.

18. Takeo $\mathrm{K}$ et al. A case of idiopathic omental hemorrhage treated by laparoscopic surgery. Nihon Rinsho Geka Gakkai Zasshi (Journal of Japan Surgical Association). 2007;68(3):710-4.

\section{Submit your manuscript to a SpringerOpen ${ }^{\circ}$ journal and benefit from:}

- Convenient online submission

- Rigorous peer review

- Immediate publication on acceptance

- Open access: articles freely available online

- High visibility within the field

- Retaining the copyright to your article 